\title{
Variations in Desired Family Size and Excess Fertility in East Africa
}

\author{
Dieudonné Ndaruhuye Muhoza, ${ }^{1}$ Annelet Broekhuis, ${ }^{2}$ and Pieter Hooimeijer ${ }^{3}$ \\ ${ }^{1}$ Applied Statistics Department, University of Rwanda, University Avenue 1, BP 117, Butare, Rwanda \\ ${ }^{2}$ International Development Studies Department, Utrecht University, P.O. Box 80115, 3508 TC Utrecht, The Netherlands \\ ${ }^{3}$ Department of Human Geography and Planning, Utrecht University, P.O. Box 80115, 3508 TC Utrecht, The Netherlands
}

Correspondence should be addressed to Dieudonné Ndaruhuye Muhoza; dieumu_res@yahoo.fr

Received 12 February 2014; Revised 23 April 2014; Accepted 30 April 2014; Published 27 May 2014

Academic Editor: Sidney R. Schuler

Copyright (C) 2014 Dieudonné Ndaruhuye Muhoza et al. This is an open access article distributed under the Creative Commons Attribution License, which permits unrestricted use, distribution, and reproduction in any medium, provided the original work is properly cited.

\begin{abstract}
This contribution studies the variation in desired family size and excess fertility in four East African countries by analyzing the combined impact of wealth, education, religious affiliation, and place of residence. The findings show an enormous heterogeneity in Kenya. Wealthy and higher educated people have fertility desires close to replacement level, regardless of religion, while poor, uneducated people, particularly those in Muslim communities, have virtually uncontrolled fertility. Rwanda is at the other extreme: poor, uneducated people have the same desired fertility as their wealthy, educated compatriots, regardless of their religion-a case of "poverty Malthusianism." The potential for family planning is high in both countries as more than $50 \%$ of the women having 5 children or more would have preferred to stop at 4 or less. Tanzania and Uganda have an intermediate position in desired family size and a lower potential for family planning. Generally, the main factor that sustains higher fertility is poverty exacerbated by religious norms among the poor only.
\end{abstract}

\section{Introduction}

The demographic developments in sub-Saharan Africa continue to puzzle population experts. After the turn of the millennium the stalling of the fertility decline in many countries gave new food for thought [1-4], while the debates continued on differential fertility change within countries $[3,5-7]$ as well as that on the unfinished family planning agenda $[8]$.

This paper investigates the levels and determinants of excess fertility in East Africa, using data from the latest Demographic and Health Surveys (DHSs). It links up with the debate on variations at the national and the community levels and aims at identifying the community contexts in these countries that shape both actual and desired fertility and then determine excess fertility and at finding possible target groups for future family planning programs.

To provide a better understanding of the regional background a condensed picture of the socioeconomic and demographic position of the countries concerned is presented in
Section 2 , along with a sketch of the family planning policies and performance. In Section 3, the theoretical background to the analysis is elaborated by building upon relevant literature. Section 4 concerns the materials and methods used. The empirical analyses and results are presented in Section 5. This is followed by the conclusion of results (Section 6).

\section{Background}

The four countries under study are members of the East African Community (EAC). The countries differ in many ways, but they all have still a predominantly rural-based society and share a modest position on the UNDP Human Development Index list [9]. Kenya occupies the relatively best position on the 2013 list, ranking 145 out of 186 countries. Rwanda ranks the lowest (167th), while Tanzania and Uganda come in at 152 and 161, respectively. Kenya owes its better position to a higher gross national product per capita and a more diversified economy, combined with a better educated 
TABLE 1: Total fertility rate and desired family size for all women (year of survey).

\begin{tabular}{|c|c|c|c|c|}
\hline Indicator & Kenya & Tanzania & Uganda & Rwanda \\
\hline Total fertility rate & $4.6(2008 / 9)$ & $5.4(2010)$ & $6.2(2011)$ & $4.6(2010)$ \\
\hline Total fertility rate (previous DHS) & $4.9(2003)$ & $6.1(2004 / 05)$ & $6.7(2006)$ & $5.8(2005)$ \\
\hline Desired family size & $3.8(2008 / 9)$ & $4.9(2010)$ & $4.8(2011)$ & $3.3(2010)$ \\
\hline Desired family size (previous DHS) & $3.9(2003)$ & $5.0(2004 / 05)$ & $5.0(2006)$ & $4.3(2005)$ \\
\hline
\end{tabular}

Source: DHSs reports.

population. Tanzania appears to be the society with the least inequality of the four countries; it has the lowest income Gini coefficient next to the highest life expectancy at birth. Rwanda stands out for its enormous population pressure; the population density (420 people per square kilometrethe highest density in Africa) is 8 times that of Tanzania (51 people per square kilometre). All countries witness a process of urbanization but the urbanization rates diverge.

Thus, although the structural socioeconomic changes that are traditionally linked to changes in demographic regime are occurring in all four countries, the pace and the extent of change are not uniform. The fertility transition is on its way with a moderate to substantial decline [10-12]. With a total fertility rate (TFR) of 4.6 births, Kenya and Rwanda have just entered the mid phase and Uganda (6.2 births) is still in the early phase of the fertility transition. Tanzania (5.4 births) is at the boundary between the early and early/mid phase (Table 1) (ranges are taken from Bongaarts 2003: early phase (6-6.9); early/mid (5-5.9); mid (4-4.9); mid/late (3-3.9); late (2.1-2.9)).

Looking at the desired fertility (Table 1), Rwanda has the lowest average preference followed by Kenya. Uganda and Tanzania with one more wanted child than Kenya and one and half more than Rwanda still favor large families. The gap between the actual fertility and the desired family size is significant in all four countries, and particularly so in Rwanda and Uganda. Despite the recent impressive decline of fertility in Rwanda, this gap still exists, because of a similar decline in desired fertility.

The family planning programs vary in duration, government support, approach, and objectives. The oldest program is that of Kenya. It received more real support from the government during the 1980s and 1990s than the programs in other countries. The program was among the best in subSaharan Africa $[13,14])$. In contrast, in Tanzania there was no support from government and the programs were exclusively focused on birth spacing in order to improve child and maternal health [15]. In Uganda, there was little government commitment to family planning programs [8], and until 1995 family planning services were limited to urban areas and to married women who were accompanied by their husbands. In Rwanda, an explicit family planning policy was adopted in 1990 in order to curb the high population growth. After the 1994 genocide, the population policy was seen in a new light, and it focused on improving the quality of life and rebuilding dislocated families. In the new millennium, a new general policy was developed and issued by the Ministry of Health [16]. This new program, like those in the neighboring countries, is more holistic in its goals for reproductive health and sustainable development $[17,18]$. Starting in 2006, Rwanda launched a large "sensitizing" campaign to promote having three children as the ideal family size. This may account for the fact that, although the drop in TFR was substantial between 2005 and 2010, excess fertility is still very high in 2010, because desired family size went down just as fast (see Table 1). Contraceptive prevalence is still limited in all four countries. The percentage is higher in Rwanda (51.6\%) and Kenya (45.5\%) and lower in Tanzania (34.4\%) and Uganda (30.0\%) [19-22].

\section{Literature Review}

3.1. Desired Fertility Theories. According to the dominant economic interpretation of fertility behavior, the main driving forces that reduce the desired fertility are structural socioeconomic transformations in societies, which lead to increasing expected costs for and diminishing benefits from children [2]. In modernizing societies, there appear new forms of investment and insurance that replace the initial function of having a large number of offspring and erode the expected benefits from children. The monetization of the economy increases awareness of the costs of raising children in terms of food, clothes, health, and education. It also creates increasing employment prospects outside the home for women $[23,24]$.

In this explanatory framework, fertility is seen as the outcome of a couple's rational and conscious decision-making. Irrespective of the type of society, couples balance the costs of having children against the expected economic, social, and psychological gains they could obtain through them. The wide application of this framework in numerous studies of fertility change, however, did not stop the debate on the driving forces of fertility decline. The first issue is whether the cost-benefit approach is equally valid in every phase of the demographic transition $[5,25]$. The second is the role of the social and cultural determinants of reproductive behavior. The value that couples attach to children is influenced by the norms and attitudes of their social surroundings, and the impact of those sociocultural determinants appears to change in character and force during the demographic transition [6, 26-29]. Some therefore state that economic and cultural approaches should be combined [2]. We will follow this approach in our analysis.

Particularly in the early to mid phases of the transition, couples are expected to conform to their community's norms and attitudes concerning reproductive behavior, because familial and social networks are important in a context where 
formal social security systems are absent and trust in state institutions is weak. People rely on their familial and social networks for access to resources and support in the case of need and will therefore not deviate strongly from the shared values and norms of their community $[13,30]$. New ideas about reproductive behavior will be picked up not from modern media but from interaction within family and community networks [27].

Several socioeconomic factors changing with socioeconomic development or family planning campaign affect the demand for children (and then excess fertility). Educational level that slows down traditional beliefs seems to be the most important. A substantial amount of empirical literature demonstrates that there is a strong negative correlation between educational level and fertility preferences and behavior [27, 31-33]. Religion, generally, operates in reverse direction, but this depends on the demographic transitional phase and varies with socioeconomic positions [34, 35]. The religious effect is higher among lower socioeconomic groups and lower and even absent among wealthy people. Residence has shown a different pattern in both desiring and achievement. Compared with rural area, urban environments offer their residents more varied opportunities in terms of labor and education for their children and are associated with cultural diversity and openness to new ideas [12] contributing to the weakening of traditional norms and values, such as the system of sharing resources making them more tolerant of small families and more in favor of family planning [36].

Regardless of the indicator used, studies show that the desired family size is negatively associated with economic position: couples with a low position desire and have more children than those with a higher position $[37,38]$. However, in some contexts that reasoning will not stand up. An adverse relationship is observed in settings of economic crisis or personal hardship [39]. In some Asian countries, women from poorer households have reported lower demand for children relative to women in the richest group [40, 41]. A study conducted in Nigeria during a period of crisis showed that respondents who stated that poverty had affected their economic expectations had lower fertility preferences than those who were indifferent or held opposing views [42]. This finding indicates that the negative impact of poverty on desired family size occurs when people are aware that they lack economic opportunities or are unable to support many children. The latter is sometimes referred to as "poverty Malthusianism" in relation to Latin American and Asian cases (Cosio-Zavala, 1995, mentioned in [43]).

Finally, the level of child mortality plays an important role to determine the desired family size and the decision to use contraception to achieve the desired one, through the mechanisms of insurance and replacement mechanisms $[44,45]$. We expect that women who have lost some children desire more children than women who have not lost children, other things being equal.

3.2. Excess Fertility and Demographic Transition. The phenomenon of excess fertility is directly related to lower fertility preferences, because a lower desired fertility can be achieved only by limiting the number of births. This requires adaptations in sexual behavior and access to and trust in contraceptive means. Unless these conditions are fulfilled, the ultimate family size will probably surpass the desired one.

According to the classical demographic transition theory, the desired fertility generally declines and excess fertility increases in the early and mid phases of the transition, following an inverted U-shaped curve $[26,46]$. In the pretransitional phase, fertility is considered "natural" and both sociocultural and economic determinants favor high fertility. Excess fertility does not occur in this phase. This situation changes as soon as the transition process takes off and the mortality risks decline. At the start, a small group in society (particularly the wealthier urban segment of the population) experiences fertility excess and a few innovators start to use contraception, but most people, even though they desire fewer children, do not practice contraception because the social and economic costs of fertility control outweigh the benefits. For an increasing number of couples, in this phase socioeconomic factors start to conflict with those related to social and cultural ones. Excess fertility rises, because couples do not stop childbearing after the desired family size is attained.

In the mid and late transitional phases, reproductive change spreads rapidly as more population groups profit from socioeconomic development and the diffusion of new ideas through social interaction processes reinforces rather than inhibits demographic change. Traditional sociocultural factors gradually lose their influence, leading to less resistance to having a limited number of offspring and a drop in the social costs of contraception. Hence, excess fertility peaks before it starts to diminish substantially. In those phases, fertility behavior is more consistent with the expectations of most demographic and economic theories of fertility [47] and cultural factors play a more limited role. In the higher socioeconomic stratum of the population, excess fertility tends to disappear, but it remains high among lower socioeconomic and rural communities. This situation has been found all over the world in countries where the fertility transition is more advanced [48, 49].

Excess fertility could be conceived as unmet need for contraception. Apart from limited access to services, four constraints influence the use of effective modern family planning methods: insufficient knowledge, fear of social disapproval, fear of side effects, and perception of husband's opposition [8]. Fear of social disapproval is a constraint that refers to the community level. The other constraints concern the individual level and relate partly to the same determinants that shape the decline in desired family size $[8,50,51]$, although the line of reasoning differs at some points. Urban residence coincides with less excess fertility, not only because of the tolerance towards the use of contraceptive means but also because of the better access to reproductive health facilities. Higher education is thought to contribute to the use of contraceptives, as mothers are expected to combine demanding jobs with reproductive duties; education also has an impact on the capability of the people in these groups to meet their need for contraceptives. It is also thought that educated women are less fearful 
of side effects and encounter less opposition from their husbands.

Most African societies are marked by gender inequities and a patriarchal social system [52]. As a consequence, women have a lower status and fertility decision-making is controlled by their male partners [53], who often do not experience the burdens of rearing many children because they leave that task to their wives. However, in family settings with a high level of interspousal communication, a desire for smaller families appears $[54,55]$. We expect that if the male partner wants more children or the woman does not know her partner's preference, a woman is likely to be in excess fertility.

\section{Materials and Methods}

4.1. Data. The data for this research are drawn from the Kenya 2008/9, Tanzania 2005, Rwanda 2010, and Uganda 2011 Demographic and Health Survey data sets [19-22]. The data are collected by means of nationally representative samples of households, and are readily comparable because the standard DHS questionnaire was used. As this study was restricted to married women or women living in a consensual union who have at least one child and reported numerical responses to the question about ideal family size, the analysis included 4,356 women from Kenya, 6,022 from Tanzania, 6,337 from Rwanda, and 4,868 from Uganda.

4.2. Dependent Variable. This study is focused on excess fertility. Excess fertility is a situation in which actual fertility exceeds desired fertility. Because of this definition, women without children were removed from this analysis. Actual fertility is the number of living, not ever born, children a woman had at the moment of interview. Desired fertility is obtained from the question on the ideal number of children, a question that aims to measure fertility preferences of the population. Excess fertility is also called unwanted fertility [26].

The dependent variable is a binary variable with value zero if the actual number of children is less than or equal to the desired number and one if otherwise. As the outcome variable is binary, having excess fertility or not, we will be using the logistic regression model that converts the outcome into a logit function, providing the probability/odds of being with excess fertility or not.

4.2.1. Binary Regression Estimation Model. In this research, excess fertility is assessed as a function of various socioeconomic and sociocultural factors that shape both the desired and actual fertility from which excess fertility is drawn. The logistic regression establishes a linear relationship between the logarithm of $P / 1-P$ called logit and independent variables.

The logistic regression model is written as follows:

$$
\operatorname{logit}(P)=\ln \left(\frac{P}{(1-P)}\right)=\beta_{0}+\beta_{1} X_{1}+\beta_{2} Y_{2}+\beta_{3} Z_{3}+\varepsilon_{i} \text {, }
$$

where $P$ is the probability of having excess fertility, $X_{i}$ represent independent variables, and $\beta_{i}$ are their estimated coefficients. $\varepsilon_{i}$ represents error term.

4.2.2. Issues Related to Desired Fertility. To obtain data about the desired number of children, two questions were used in the DHS questionnaire. The one for women with children was: "If you could go back to the time you did not have any children and could choose exactly the number of children to have in your whole life, how many would that be?" Although responses to these questions should be integer values, between 1.1 and 7.3 per cent of respondents gave nonnumerical answers, such as "It depends on God," "As many as I can support," or "As many as my husband wishes." These respondents were removed from the data set, although it is acknowledged that this exclusion may have distorted the results. However, considering the limited number of excluded respondents, the bias is acceptable.

These questions about the ideal number of children are aimed at measuring the reproductive norms in the population and providing a quantitative basis for assessing variation in desired and actual fertility. The desired fertility also enables the calculation of excess fertility through the comparison of desired and actual fertility. Despite this important objective, responses to the question about the ideal number of children, as an indicator of the desired fertility, have been criticized regarding their validity and reliability [56], particularly for the African context [57].

The first criticism relates to the survey questions themselves and the answers they elicit. The answers could be misleading, as they reflect unformed, ephemeral views that change during the life course, and the effects of child mortality risks are not explicitly taken into account in the questions. Respondents presumably do not include possible child deaths in their ideal family size and may need to bear additional children in order to achieve that size. Thus, the total number of births in a marriage may exceed the desired familysize without any child being unwanted [58]. To meet this objection we included mortality experiences in the model.

The second criticism is that there could be a rationalization of the desired family size to the actual family size. Despite the likelihood that some rationalization occurs, many respondents report ideal sizes that are lower or higher than their actual number of surviving children, also in East Africa (Tables 1 and 2). Only between 11 and 25 per cent of all women reported their actual number of children as ideal, and between 12 and 36 per cent reported their actual fertility as exceeding their desired fertility. Some 21 to 72 per cent of women with 5 children reported excess.

At parity 8 and more, 59 to 87 per cent of the women declared to be with excess fertility. Even if there is rationalization in some cases, this does not apply to the majority of the respondents who had a high number of surviving children. The correlation coefficients between the number of surviving children and the ideal number show a weak relationship; the values range from 0.32 for Rwanda to 0.34 for Kenya, 0.43 for Tanzania, and 0.31 for Uganda. 
Table 2: Percentage of women with two children or more whose desired fertility is greater than, equal to, or less than their actual fertility.

\begin{tabular}{lccccccccc}
\hline \multirow{2}{*}{ Country } & \multirow{2}{*}{ Category of desired fertility } & & \multicolumn{5}{c}{ Number of living children } \\
& & 2 & 3 & 4 & 5 & 6 & 7 & $8+$ & Total \\
\hline \multirow{3}{*}{ Kenya } & Greater & 72.7 & 59.3 & 33.1 & 29.7 & 25.9 & 22.8 & 18.3 & 47.7 \\
& Equal & 24.7 & 24.0 & 41.5 & 16.5 & 21.2 & 11.1 & 13.9 & 24.8 \\
& Less & 2.6 & 16.7 & 25.4 & 53.8 & 52.9 & 66.3 & 67.8 & 27.5 \\
\hline \multirow{3}{*}{ Tanzania } & Greater & 96.2 & 92.0 & 72.1 & 59.9 & 42.9 & 42.8 & 26.1 & 77.3 \\
& Equal & 3.7 & 6.4 & 21.6 & 19.0 & 29.0 & 13.0 & 15.0 & 10.8 \\
& Less & 0.2 & 1.6 & 6.3 & 21.2 & 28.2 & 44.3 & 58.9 & 11.9 \\
\hline \multirow{3}{*}{ Uganda } & Greater & 93.2 & 87.3 & 59.5 & 55.4 & 32.0 & 31.5 & 15.4 & 60.8 \\
& Equal & 5.7 & 6.3 & 32.0 & 13.0 & 26.0 & 8.1 & 7.7 & 14.2 \\
& Less & 1.0 & 6.4 & 8.5 & 31.6 & 42.0 & 60.4 & 76.9 & 25.0 \\
\hline \multirow{3}{*}{ Rwanda } & Greater & 82.3 & 55.8 & 23.6 & 16.6 & 11.0 & 10.6 & 6.1 & 41.5 \\
& Equal & 17.0 & 33.6 & 39.2 & 11.7 & 10.7 & 4.0 & 6.5 & 22.1 \\
& Less & 0.7 & 10.6 & 37.2 & 71.7 & 78.3 & 85.4 & 87.4 & 36.4 \\
\hline
\end{tabular}

Source: computation from the datasets.

The third criticism is that responses from women alone may not describe the real norms that guide fertility decisions. The attitudes of other family members, especially husbands or partners, may exert a great influence on reproductive decisions, particularly in sub-Saharan Africa where stronger unbalanced gender relations prevail. In practice, however, the importance of this criticism is doubtful. The evidence from surveys in which both husbands and wives were interviewed suggests that there is no radical difference between the views of the two sexes [59]. In East Africa, the evidence is mixed; in Rwanda, men desire fewer children than women, but in the other three countries their preference is higher than that of women. In this study we address this specific problem by including the husband's desire in the model of excess fertility reported by the women.

4.3. Independent Variables. Excess fertility was modeled as a function of various socioeconomic and sociocultural variables that define communities which are the focus point of this research. We have restricted the analysis to socioeconomic and cultural variables, because they are exogenous to the dependent variable. Demographic factors, like mortality, have been excluded from the analysis since they operate through the components of excess fertility, namely, actual and desired fertility. Only the number of living children is used as it is an important variable of control. Also, in order to avoid the problem of endogeneity, such proximate determinants as knowledge of contraception and approval of contraception were not included in the analysis.

We shall note that socioeconomic and sociocultural factors operate differently. While the first group leads to desired lower fertility, the second is expected to reflect a pronatalist attitude. To check the effect of communities on the excess fertility, an interaction effect of the religious affiliation with educational level was included. For more details about independent variables and their categories, see Table 3.

\section{Results}

As stated early, this study is focused on excess fertility which is defined in reference to desired and actual fertility. To understand the existence of excess fertility, our analysis starts with descriptive statistics on desired fertility that show the variability of demand for children between and within countries. Descriptive statistics are presented with respect to the two important socioeconomic and sociocultural factors that define communities of interest, mainly educational level and religion.

5.1. Economic and Religious Differentials in Desired Fertility between Countries. According to Table 4 displaying the variations of desired fertility in terms of ideal number of children, it appears clearly that East Africa countries do not have the same attitude toward fertility and within the same country different communities have different aspirations regarding family size.

Kenya exhibits the largest diversity of fertility preferences according to either religious communities or socioeconomic ones. Rwanda has the lowest diversity. In Kenya, Muslims desire nearly twice the number of children desired by Christians (6.7 versus 3.8) whereas in Rwanda they desire slightly less than Christians, but the difference is small (3.4 versus 3.6). The homogeneity between religious communities is also a feature of Uganda, yet with higher preferences than in Rwanda: 5.2 children for Muslims and 5.3 for Christians. Tanzania occupies an intermediate position: Muslims prefer one more child than Christians, respectively, 6 and 5 children.

The differences in fertility preferences appear also when considering educational or economic communities. With regard to education, irrespective of religion, the differences are clear and straightforward in all countries. The desired fertility decreases progressively with the level of education. However, there are large variations across religious communities. The gap between women with no education and those 
TABLE 3: Percentage distribution of respondents by background characteristics.

\begin{tabular}{|c|c|c|c|c|c|c|c|c|c|}
\hline \multirow{2}{*}{ Variable } & \multirow{2}{*}{ Categories } & \multicolumn{2}{|c|}{ Kenya } & \multicolumn{2}{|c|}{ Tanzania } & \multicolumn{2}{|c|}{ Uganda } & \multicolumn{2}{|c|}{ Rwanda } \\
\hline & & $\%$ & $N$ & $\%$ & $N$ & $\%$ & $N$ & $\%$ & $N$ \\
\hline \multirow{4}{*}{ Woman's education } & No education & 15.0 & 653 & 28.9 & 1742 & 19.3 & 941 & 19.6 & 1242 \\
\hline & Inc. primary & 29.3 & 1278 & 16.5 & 992 & 46.0 & 2237 & 54.5 & 3458 \\
\hline & Comp. primary & 26.5 & 1155 & 45.4 & 2732 & 11.2 & 545 & 14.7 & 930 \\
\hline & Secondary and + & 29.3 & 1279 & 9.2 & 556 & 23.5 & 1145 & 11.2 & 707 \\
\hline \multirow{4}{*}{ Woman's occupation } & Cultivator & 26.5 & 1157 & 70.6 & 4253 & 52.9 & 2575 & 76.5 & 4846 \\
\hline & Craftswoman & 4.9 & 215 & 11.4 & 685 & - & - & 4.1 & 259 \\
\hline & Works in services & 30.9 & 1350 & 4.4 & 265 & 27.5 & 1339 & 9.2 & 584 \\
\hline & Others & 37.6 & 1643 & 13.6 & 819 & 19.6 & 954 & 10.2 & 648 \\
\hline \multirow{4}{*}{ Woman's religion } & Catholic & 19.4 & 848 & 23.3 & 1403 & 43.8 & 2134 & 42.4 & 2685 \\
\hline & Protestant & 62.8 & 2740 & 23.6 & 1423 & 41.3 & 2012 & 54.2 & 3432 \\
\hline & Muslim & 13.7 & 598 & 42.6 & 2563 & 13.8 & 671 & 1.6 & 99 \\
\hline & Others & 4.1 & 179 & 10.5 & 633 & 1.0 & 51 & 1.9 & 121 \\
\hline \multirow{4}{*}{ Partner's education } & No education & 11.2 & 491 & 19.4 & 1167 & 11.3 & 551 & 19.5 & 1235 \\
\hline & Inc. primary & 18.7 & 818 & 18.9 & 1136 & 36.7 & 1787 & 50.9 & 3225 \\
\hline & Comp. primary & 28.2 & 1233 & 48.7 & 2935 & 15.8 & 767 & 16.2 & 1028 \\
\hline & Secondary and + & 41.8 & 1823 & 13.0 & 784 & 36.2 & 1080 & 13.4 & 849 \\
\hline \multirow{5}{*}{ Wealth index } & Poorest & 20.2 & 882 & 18.7 & 1129 & 23.0 & 1120 & 19.5 & 1237 \\
\hline & Poorer & 16.4 & 715 & 19.4 & 1170 & 18.7 & 911 & 19.9 & 1264 \\
\hline & Middle & 18.0 & 785 & 19.2 & 1159 & 17.1 & 831 & 19.7 & 1248 \\
\hline & Richer & 19.4 & 847 & 23.0 & 1386 & 16.4 & 797 & 20.3 & 1289 \\
\hline & Richest & 26.0 & 1136 & 19.6 & 1178 & 24.8 & 1209 & 20.5 & 1299 \\
\hline \multirow{2}{*}{ Type of residence } & Urban & 27.8 & 1213 & 20.2 & 1218 & 24.2 & 1180 & 14.8 & 937 \\
\hline & Rural & 72.2 & 3152 & 79.8 & 4804 & 75.8 & 3688 & 85.2 & 5400 \\
\hline \multirow{4}{*}{ Partner desire for children } & Same & 51.0 & 2228 & 39.0 & 2347 & 28.3 & 1376 & 58.0 & 3675 \\
\hline & More & 18.6 & 813 & 32.4 & 1948 & 28.6 & 1390 & 10.5 & 663 \\
\hline & Fewer & 6.3 & 273 & 4.5 & 273 & 8.8 & 426 & 17.9 & 1136 \\
\hline & Don't know & 24.1 & 1051 & 24.1 & 1454 & 34.4 & 1676 & 13.6 & 863 \\
\hline \multicolumn{2}{|c|}{ No living children: mean (StD) } & \multicolumn{2}{|c|}{$3.4(2.09)$} & \multicolumn{2}{|c|}{$3.6(2.26)$} & \multicolumn{2}{|c|}{$4.03(2.34)$} & \multicolumn{2}{|c|}{$3.5(2.0)$} \\
\hline Total & & 100 & 4365 & 100 & 6022 & 100 & 4868 & 100 & 6337 \\
\hline
\end{tabular}

Source: computation from the datasets.

TABLE 4: Mean ideal number of children by country according to religion, education, and wealth.

\begin{tabular}{|c|c|c|c|c|c|c|c|c|}
\hline \multirow{3}{*}{ National level } & \multirow{2}{*}{\multicolumn{2}{|c|}{$\begin{array}{c}\text { Kenya } \\
4.3\end{array}$}} & \multirow{2}{*}{\multicolumn{2}{|c|}{$\begin{array}{c}\text { Tanzania } \\
5.7\end{array}$}} & \multirow{2}{*}{\multicolumn{2}{|c|}{$\begin{array}{c}\text { Uganda } \\
5.3\end{array}$}} & \multirow{2}{*}{\multicolumn{2}{|c|}{$\begin{array}{c}\text { Rwanda } \\
3.6\end{array}$}} \\
\hline & & & & & & & & \\
\hline & Christians & Muslims & Christians & Muslims & Christians & Muslims & Christians & Muslims \\
\hline \multicolumn{9}{|l|}{ Educational level } \\
\hline No education & 5.9 & 8.3 & 5.8 & 7.0 & 6.8 & 6.5 & 4.0 & 4.0 \\
\hline Inc. primary & 4.1 & 5.6 & 5.4 & 6.1 & 5.3 & 5.3 & 3.6 & 3.2 \\
\hline Comp. primary & 3.7 & 5.1 & 4.9 & 5.1 & 4.7 & 5.1 & 3.5 & 3.1 \\
\hline Secondary and + & 3.2 & 3.9 & 3.6 & 5.7 & 4.2 & 4.4 & 3.5 & 3.5 \\
\hline \multicolumn{9}{|l|}{ Wealth index } \\
\hline Poorest & 4.9 & 8.3 & 5.8 & 6.3 & 6.3 & 6.0 & 3.6 & 3.4 \\
\hline Poorer & 4.0 & 7.4 & 5.5 & 6.3 & 5.1 & 5.7 & 3.7 & 3.6 \\
\hline Middle & 4.0 & 5.9 & 5.3 & 6.4 & 5.2 & 5.4 & 3.6 & 2.6 \\
\hline Richer & 3.6 & 5.4 & 4.9 & 6.2 & 5.3 & 5.1 & 3.8 & 4.0 \\
\hline Richest & 3.1 & 4.5 & 3.9 & 5.1 & 4.3 & 4.7 & 3.5 & 3.2 \\
\hline Total Religion & 3.8 & 6.7 & 5.1 & 6.0 & 5.3 & 5.2 & 3.6 & 3.4 \\
\hline
\end{tabular}

Source: computation from the datasets. 


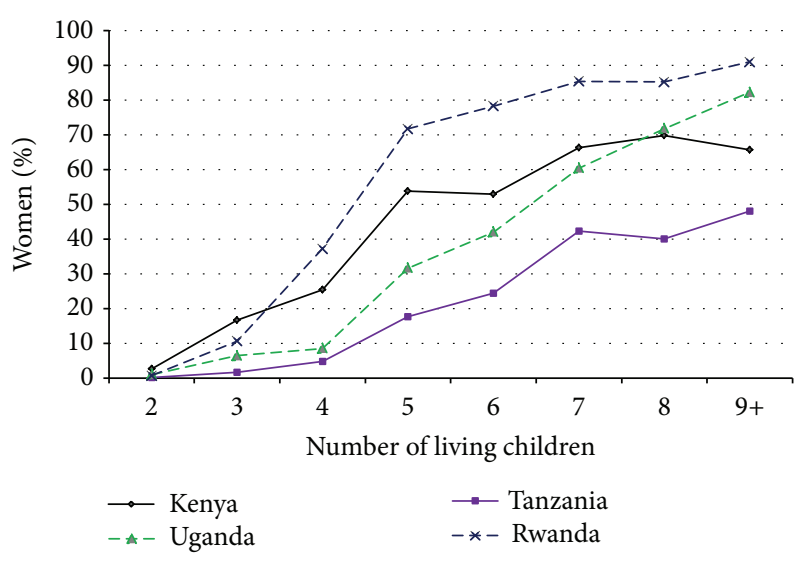

FIGURE 1: Percentage of women having excess fertility according to number of living children (source: Table 2).

who have reached the secondary school or more between Christians and Muslims is striking only in Kenya where the gap is 2.7 for Christians and 4.4 for Muslims. In all other countries the gap is very limited: less than one child.

With reference to economic status measured with wealth index of households, the pattern is similar to education, but the differences are less pronounced, except for Muslims in Kenya where the lowest quintile desires 3.8 more children than the highest. Everywhere else, the gap is lower than 2.0 children.

Considering the variations between religious communities in the same socioeconomic stratum, Table 4 indicates that the differences are substantially important only among the lower stratum (noneducated or poorest). Among higher educated or wealthier, the differences are limited and even vanish. Among noneducated women, the differences between Christians and Muslims vary between 0.0 children in Rwanda and 2.4 children in Kenya, while among the higher educated the differences are insignificant (less than one child) except in Tanzania where they remain at 2.1 children. An identical pattern is observed with regard to the wealth index. These results indicate that the religious conservatism remains among less educated communities while among the higher educated and richer it disappears.

5.2. Level of and Factors Associated with Excess Fertility. The differentiation in excess fertility is demonstrated through a graph that indicates the level of excess and a regression analysis which identify the determinants.

Figure 1 shows for each country the proportions of women with excess fertility according to their actual number of children. The graph clearly illustrates that excess fertility starts at different parities and changes at varying paces. In Kenya and Rwanda, some of the women with three or four children already reported having excess fertility, while this commences after parity 4 in the other countries. The graph shows a gradual increase in the proportion of women with excess fertility in all countries, except Rwanda where a sharp increase is to be seen after parity 3 . For parity 4 and higher, Rwanda has the highest proportions of women with more children than desired, while their Tanzanian sisters show the lowest percentages. Among Tanzanian women with five children, less than $20 \%$ of the women reported excess fertility. At parity 9, 90\% of the women in Rwanda are in excess fertility as opposed to only $50 \%$ in Tanzania.

These results indicate that a very substantial number of Rwandan and Kenyan women would want to limit their childbearing earlier than women in the other countries. In Kenya and Rwanda, we even find a category that would have preferred to stop at three children.

The results of the binary logistic regression are shown as log-odds ratios in Table 5. The most dominant factor is the number of children, which has a very strong positive effect. Even after logarithmic transformation the relation between the number of children and the odds of being in excess fertility is not linear. The effect of an extra child on excess fertility is much higher if a woman has three to five children than if she has six or more. To capture this effect we included in the model the square of the number of children. The effect of an extra child is much stronger in Rwanda than in the other countries, indicating that excess fertility there starts at a lower number. The reference category of poor, uneducated rural Catholics in this country with 5 children has a log-odd of $0.809(=-9.511+3.029 * 5+-0.193 * 25)$ meaning $69 \%$ would prefer to have fewer children. For Kenya this is $17 \%$ and for Tanzania and Uganda it is as low as 9\% and 5\% of these women, respectively. Again it is found that the other variables hardly enter the equation in Rwanda. This country is very homogeneous in terms of both the desired number and the awareness of excess fertility. The poor are just as aware of having too many children as the wealthy.

Looking at the other factors, again it turns out that the heterogeneity in the awareness of excess fertility is most prominent in Kenya. The effects of education of the woman and her partner are highly positive, as is the effect of increasing wealth. The higher socioeconomic classes in this country not only want fewer children, but are also more aware of having too many. Muslims provide a special case again. Given the actual number of children they have, few of the uneducated indicated that they would have preferred fewer children (-2.35). However, this is offset by the interaction effect of the higher educated Muslims (+2.19), meaning that this group is just as aware of excess fertility as higher educated Catholics or Protestants.

In Tanzania, the role of education is less pronounced and the women's educational level is not even significant. The effect of increasing wealth is stronger than it is in Kenya. Even the better educated Muslims are less aware of excess fertility than their Christian counterparts. Tanzania is the country in which religious affiliation has an impact on fertility preferences for all socioeconomic strata. Uganda resembles Kenya in the role of education, of both women and their partners, but the effects of wealth and religion are completely different; the poor are more aware of having too many children than the Ugandan middle and richer classes even if the results are not significant. Just as in Rwanda, this could be interpreted as a form of "poverty Malthusianism." Women are aware that they do not have the means to support large families. Religion does not play a significant role in this awareness. 
TABLE 5: Log odds of being in excess fertility from the binary logistic regression.

\begin{tabular}{|c|c|c|c|c|}
\hline Variable & Kenya & Tanzania & Uganda & Rwanda \\
\hline Constant & $-8.236^{* * *}$ & $-10.138^{* * *}$ & $-9.610^{* * *}$ & $-9.511^{* * *}$ \\
\hline No living children & $1.809^{* * *}$ & $2.064^{* * *}$ & $1.715^{* * *}$ & $3.029^{* * *}$ \\
\hline No living children squared & $-0.096^{* * *}$ & $-0.100^{* * *}$ & $-0.073^{* * *}$ & $-0.193^{* * *}$ \\
\hline \multicolumn{5}{|l|}{ Residence (ref. rural) } \\
\hline Urban & -0.078 & 0.153 & $0.316^{* *}$ & -0.020 \\
\hline \multicolumn{5}{|c|}{ Woman's religion (ref. catholic) } \\
\hline Protestant & -0.124 & -0.180 & $0.441^{* *}$ & -0.036 \\
\hline Muslim & $-2.352^{* * *}$ & $-1.182^{* * *}$ & 0.085 & -0.649 \\
\hline Others & $-1.374^{* * *}$ & $-0.782^{* * *}$ & 0.555 & 0.155 \\
\hline \multicolumn{5}{|c|}{ Woman education (ref. no education) } \\
\hline Inc. primary & 0.481 & 0.075 & $0.756^{* * *}$ & 0.145 \\
\hline Com. primary & $1.053^{* * *}$ & 0.162 & $1.173^{* * *}$ & 0.331 \\
\hline Secondary and + & $0.697^{*}$ & 0.279 & $1.404^{* * *}$ & $0.790^{* * *}$ \\
\hline \multicolumn{5}{|c|}{ Husband education (ref. no education) } \\
\hline Inc. primary & $0.799^{* * *}$ & $0.270^{*}$ & $0.875^{* * *}$ & 0.074 \\
\hline Com. primary & $0.898^{* * *}$ & $0.292^{*}$ & $0.796^{* * *}$ & $0.232^{*}$ \\
\hline Secondary and + & $0.629^{* * *}$ & 0.140 & $0.950^{* * *}$ & -0.083 \\
\hline \multicolumn{5}{|c|}{ Woman occupation (ref. cultivator) } \\
\hline Craftswoman & $-0.932^{* * *}$ & 0.049 & $(-)$ & 0.121 \\
\hline Worker in service & -0.126 & $0.590^{* *}$ & 0.170 & -0.019 \\
\hline Others & $-0.299^{* *}$ & -0.126 & -0.146 & $-0.303^{* *}$ \\
\hline \multicolumn{5}{|l|}{ Wealth index (ref. poorest) } \\
\hline Poor & $0.475^{* * *}$ & 0.273 & 0.133 & -0.190 \\
\hline Middle & $0.361^{* *}$ & $0.331^{* *}$ & 0.090 & -0.080 \\
\hline Richer & $0.548^{* * *}$ & $0.656^{* * *}$ & 0.001 & $-0.378^{* * *}$ \\
\hline Richest & $0.531^{* *}$ & $1.125^{* * *}$ & 0.042 & -0.180 \\
\hline \multicolumn{5}{|c|}{ Husband desire for children (ref. same) } \\
\hline More & $0.852^{* * *}$ & $0.261^{* *}$ & $0.434^{* * *}$ & -0.017 \\
\hline Fewer & 0.303 & 0.172 & $-0.379^{* *}$ & -0.133 \\
\hline DK & $0.212^{*}$ & 0.146 & 0.115 & -0.174 \\
\hline \multicolumn{5}{|c|}{ Interaction effects } \\
\hline \multicolumn{5}{|c|}{ Protestant/education (ref. no education) } \\
\hline Inc. primary & 0.169 & -0.078 & -0.418 & -0.033 \\
\hline Com. primary & -0.391 & 0.289 & $-0.737^{* *}$ & -0.433 \\
\hline Secondary and + & 0.324 & 0.855 & $-0.599^{*}$ & $-0.532^{*}$ \\
\hline \multicolumn{5}{|c|}{ Muslim/education (ref. no education) } \\
\hline Inc. primary & $1.327^{* *}$ & 0.463 & -0.579 & 0.776 \\
\hline Com. primary & 0.793 & $0.923^{* * *}$ & -0.523 & 1.247 \\
\hline Secondary and + & $2.194^{* * *}$ & -0.132 & $-0.840^{*}$ & -1.352 \\
\hline \multicolumn{5}{|c|}{ Other religions/education (ref. no education) } \\
\hline Inc. primary & 0.464 & 0.168 & -0.725 & 0.524 \\
\hline Com. primary & -1.100 & -0.025 & 0.188 & 0.745 \\
\hline Secondary and + & 1.819 & $(-)$ & $(-)$ & -0.679 \\
\hline Pseudo- $R^{2}$ & 0.513 & 0.493 & 0.527 & 0.631 \\
\hline$N$ & 4365 & 6022 & 4868 & 6337 \\
\hline
\end{tabular}

${ }^{*}$ Significant at $10 \%$ level, ${ }^{* *}$ significant at $5 \%$ level, and ${ }^{* * *}$ significant at $1 \%$ level.

$(-)$ indicates that there are insufficient cases in this category to calculate a coefficient. 
TABle 6: Parity (mean number of children) at which excess fertility starts to be dominant (>50\%) within women for highest and lowest socioeconomic classes by religion.

\begin{tabular}{|c|c|c|c|c|c|c|}
\hline \multirow{3}{*}{ Country } & \multicolumn{6}{|c|}{ Religion } \\
\hline & \multicolumn{2}{|c|}{ Catholic } & \multicolumn{2}{|c|}{ Protestant } & \multicolumn{2}{|c|}{ Muslim } \\
\hline & Highest category & Lowest category & Highest category & Lowest category & Highest category & Lowest category \\
\hline Kenya & 5 & 8 & 5 & 8 & 6 & $\mathrm{UF}^{*}$ \\
\hline Tanzania & 5 & 8 & 5 & 9 & 7 & $\mathrm{UF}^{*}$ \\
\hline Uganda & 6 & 9 & 6 & 8 & 7 & 9 \\
\hline Rwanda & 4 & 5 & 5 & 5 & 5 & 5 \\
\hline
\end{tabular}

* Uncontrolled fertility, meaning that at no parity is the majority of the women in excess fertility.

Source: computation from the results of the model in Table 4.

A striking outcome for all countries, except Uganda, is that the effect of the urban/rural divide disappears after controlling levels of education, occupational structure, wealth, and religious composition. The urban/rural dichotomy is a container concept that captures the socioeconomic and sociocultural differentiation of the population rather than being an explanatory factor in itself. Table 6 summarizes the differential role of religion and socioeconomic well-being in the four countries, by showing the estimate of the number of children at which a majority of the women indicate they would have wanted fewer children.

It confirms the conclusion that in Kenya and Tanzania there is a large contrast between the wealthiest and best educated part of the population on the one hand, and the poor, uneducated part on the other. In these countries, even at parity 12 or higher, fewer than $50 \%$ of the poor uneducated Muslim women are estimated to be in excess fertility. Given the fact that they also want many children, this means that the preferences of these women are near to uncontrolled fertility. Uganda does not show any signs of religious differentials but Kenya and Tanzania exhibit important social-economic contrasts. In Rwanda, having more than four or five children is problematic in all strata of society.

\section{Discussion and Conclusion}

There are remarkable differences in desired and excess fertility between the four East African countries and between certain communities in those countries. The differences are largest in Kenya and smallest in Rwanda, while Tanzania and Uganda occupy intermediate positions. Our outcomes also contribute to the understanding that both socioeconomic and sociocultural factors should be taken into consideration when studying the fertility behavior and that relations that hold for one community in a country are of no or less importance for another. New attitudes to desired family size diffuse along different paths within the various communities in a specific national context.

The effect of education-which is known to be one of the most important determinants of change in fertility attitudes and behavior-differs widely between the religious communities in a country. This difference probably relates to the minority status of these communities, and perhaps also to the strong social cohesion and control within them. The large communities of poor/uneducated Muslims in Kenya and Tanzania in particular seem to differ in reproductive norms from the Christian communities. The proportion of Muslims in Rwanda is very small, and the difference between religions communities is absent. The variation within religious subgroups undermines the role ascribed to religion. To get a clear picture of the significance of religion, a more precise categorization of religious communities would be preferable in future research.

The finding that the variation in desired family size and excess fertility according to religion within the socioeconomic strata in every country is limited supports the conclusion that the main factor that sustains the higher demand for children in sub-Saharan Africa is poverty rather than religious norms. However, the most remarkable outcome of our analysis is the consensus among Rwandan population groups regarding desired fertility and excess fertility. This country shows homogeneity in desired family size for the various communities with only a few determinants displaying some significant impact. Contrary to the other East African countries, the awareness of being in excess fertility is found among all Rwandan communities. This limited differentiation can be understood if the current land problems are taken into account. The desire for fewer children might be a result of population pressure on the land and a lack of labor opportunities outside agriculture, which negate any current or future benefits from children's work. Instead, children are seen as a burden in terms of extra mouths to feed and extra outlay on school fees, clothes, and health care. These findings confirm the assumption that the desired fertility is the outcome of parents' assessment of the costs and benefits of their offspring, besides the future opportunities of their children. Land problems would also explain why in Rwanda excess fertility is higher among agrarian and poorer communities than it is among similar communities in neighboring countries. It indicates that Rwanda is likely to be undergoing a type of demographic transition that in Latin America and Asia is called "poverty Malthusianism." Its fertility decline does not depend on socioeconomic development, but is induced by poverty and a lack of income-generating activities.

The last implication of our findings is that low desired fertility is a necessary but not a sufficient condition to bring down actual fertility; unmet need is also a major determinant. Rwanda provides a good example. The sensitizing campaign brought about a sharp decrease in desired family size to 3.3 in 2010. The expansion of reproductive health services was 
therefore welcomed by the population, leading to a very large drop in actual fertility to 4.6 in 2010 . Yet excess fertility is still prominent and the potential for further reduction by improving access to services is still high. In other countries the situation is more complex.

In Kenya, there is a need to orient the campaign towards specific communities that are still in a pretransitional phase of fertility transition. Without a reduction of desired fertility, family planning programs will not be effective. In Tanzania, the high desired fertility and low access to family planning are both determinants of the high fertility. Therefore, family planning programs should focus on both aspects, that is, they should aim at reducing higher desired fertility and at meeting the need for family planning. Family planning programs should be more oriented towards certain groups, such as rural Muslims and poorer people.

\section{Appendix}

For details see Table 3 .

\section{Conflict of Interests}

The authors declare that there is no conflict of interests regarding the publication of this paper.

\section{References}

[1] J. Bongaarts, “The causes of stalling fertility transitions," Studies in Family Planning, vol. 37, no. 1, pp. 1-16, 2006.

[2] J. Bongaarts, "Fertility Transitions in Developing Countries: Progress or Stagnation?” Population Council, New York, NY, USA, Working Paper no. 7, 2008.

[3] C. F. Westoff and A. R. Cross, "The Stall in the Fertility Transition in Kenya," DHS Analytical Studies 9, ORC, Macro Calverton, Md, USA, 2006, http://www.econ.upf.edu/ montalvo/sec1034/jde.pdf.

[4] D. Shapiro and T. Gebreselassie, "Fertility transition in SubSaharan Africa: falling and stalling," Etude de la Population Africaine, vol. 23, no. 1, pp. 3-23, 2008.

[5] A. Ezeh, B. Mberu, and J. Emina, "Patterns of Stall in Fertility Decline and their determinants in Eastern Africa," Nairobi, African Population and Health Research Center, 2009, http:// paa2009.princeton.edu/download.aspx?submission $=91330$.

[6] B. Nauck, "Value of of children and the framing of fertility: results from a cross-cultural comparative survey in 10 societies," European Sociological Review, vol. 23, no. 5, pp. 615-629, 2007.

[7] K. O. Mason and A. M. Jensen, Gender and Family Change in Industrialised Countries, Clarendon Press, Oxford, UK, 1995.

[8] J. Cleland, S. Bernstein, A. Ezeh, A. Faundes, A. Glasier, and J. Innis, "Family planning: the unfinished agenda," The Lancet, vol. 368, no. 9549, pp. 1810-1827, 2006.

[9] UNDP, "Human Development Report 2013: The Rise of the South: Human Progress in a Diverse World," New York, NY, USA, 2013.

[10] A. Hinde and A. J. Mturi, "Recent trends in Tanzanian fertility," Population Studies, vol. 54, no. 2, pp. 177-191, 2000.

[11] J. Blacker, "Kenya's fertility transition: how low will it go? Paper presented to the Expert Meeting on Completing the
Fertility Transition," United Nations-Population Division, ESA/P/WP.172 Proceedings, New York. NY, USA, 2002, http:// www.un.org/esa/population/publications/completingfertility/ RevisedBlackerpaper.PDF.

[12] M. Garenne and V. Joseph, "The timing of the fertility transition in sub-Saharan Africa," World Development, vol. 30, no. 10, pp. $1835-1843,2002$.

[13] J. C. Caldwell and P. Caldwell, "The cultural context of high fertility in sub-Saharan Africa," Population \& Development Review, vol. 13, no. 3, pp. 409-437, 1987.

[14] J. C. Caldwell and P. Caldwell, "Africa: the new family planning frontier," Studies in Family Planning, vol. 33, no. 1, pp. 76-86, 2002.

[15] M. Oliff, P. Mayaud, R. Brugha, and A. M. Semakafu, "Integrating reproductive health services in a reforming health sector: the case of Tanzania," Reproductive Health Matters, vol. 11, no. 21, pp. 37-48, 2003.

[16] J. Solo, "Family Planning in Rwanda: how a taboo topic became priority number one," IntraHealth, 2008, http://www.ppdafrica .org/docs/SEAPACOH2010/fpRwanda.pdf.

[17] J. Ross and J. Stover, "The family planning program effort index: 1999 cycle," International Family Planning Perspectives, vol. 27, no. 3, pp. 119-129, 2001.

[18] P. Vimard, "Africa and its demographic challenge: an uncertain future," Agence Française de Développement, Paris, France, Working paper No. 62, 2008.

[19] DHSa, "Uganda Demographic and Health Survey 2011," Kampala, Bureau of Statistics of Uganda and ORC Macro International Inc, Calverton, Md, USA, 2012.

[20] DHSb, "Rwanda Demographic and Health Survey of 2010," Kigali, National Institute of Statistics and ORC Macro International Inc, Calverton, Md, USA, 2012.

[21] DHSc, “Tanzania Demographic and Health Survey 2004-2005," Dar es Salaam, National Bureau of Statistics and ORC Macro International Inc, Calverton, Md, USA. 2005.

[22] DHSd, "Kenya Demographic and Health Survey 2008/9," Nairobi, Central Bureau of Statistics of Kenya/Ministry of Health and ORC Macro International Inc, Calverton, Md, USA, 2010.

[23] R. Andorka, Determinants of Fertility in Advanced Societies, Methuen \& Co., London, UK, 1978.

[24] J. Cleland and C. Wilson, "Demand theories of the fertility transition: an iconoclastic view," Population Studies, vol. 41, no. 1, pp. 5-30, 1987.

[25] W. C. Robinson, "The economic theory of fertility over three decades," Population Studies, vol. 51, no. 1, pp. 63-74, 1997.

[26] R. A. Easterlin, R. A. Pollack, and M. L. Wachter, "Toward a more general economic model of fertility determination: endogenous preferences and natural fertility (81-150)," in Population and Economic Change in Developing Countries, R. Easterlin, Ed., University of Chicago Press, London, UK, 1980.

[27] J. Bongaarts, "The end of the fertility transition in the developing world," Paper presented to the Expert Meeting on Completing the Fertility Transition, United NationsPopulation Division, New York, NY, USA, ESA/P/WP.172 Proceedings, 2002, http://www.un.org/esa/population/publi cations/completingfertility/RevisedBONGAARTSpaper.PDF.

[28] C. Hakim, "A new approach to explaining fertility patterns: preference theory," Population and Development Review, vol. 29, no. 3, pp. 349-374, 2003. 
[29] R. A. Pollak and S. C. Watkins, "Cultural and economic approaches to fertility: proper marriage or mesalliance?" Population \& Development Review, vol. 19, no. 3, pp. 467-496, 1993.

[30] D. J. Smith, "Contradictions in Nigeria's fertility transition: the burdens and benefits of having people," Population and Development Review, vol. 30, no. 2, pp. 221-238, 2004.

[31] T. C. Martin, "Women's education and fertility: results from 26 demographic and health surveys," Studies in Family Planning, vol. 26, no. 4, pp. 187-202, 1995.

[32] A. M. Basu, "Why does education lead to lower fertility? A critical review of some of the possibilities," World Development, vol. 30, no. 10, pp. 1779-1790, 2002.

[33] J. Cleland, "Education and future fertility trends, with special reference to mid-transitional countries," in Completing the Fertility Transition-Part 2. Background Papers, pp. 187-202, United Nations, Population Division, Department of Economic and Social Affairs, New York, NY, USA, 2002.

[34] J. Chamie, "Religious differentials in fertility: Lebanon, 1971," Population Studies, vol. 31, no. 2, pp. 365-382, 1977.

[35] R. H. Chaudhury, "Hindu-Muslim differential fertility: how much religious and how much socio?" Social action, vol. 34, no. 3, pp. 251-273, 1984.

[36] E. Gurmu and R. Mace, "Fertility decline driven by poverty: the case of Addis Ababa, Ethiopia," Journal of Biosocial Science, vol. 40, no. 3, pp. 339-358, 2008.

[37] D. E. Hyatt and W. J. Milne, "Determinants of fertility in urban and rural Kenya: estimates and a simulation of the impact of education policy," Environment and Planning A, vol. 25, no. 3, pp. 371-382, 1993.

[38] D. R. Gwatkin, S. Rutstein, K. Johnson, E. Suliman, A. Wagastaff, and A. Amouzou, "Socio-economic differences in health, nutrition and population in developing countries: an overview," in Health, Nutrition, and Population, Country Reports on HNP and Poverty, The World Bank, Washington, DC, USA, 2007.

[39] B. Egerö, "Poverty and fertility: reproductive change under persistent poverty," Yearbook of Population Research in Finland, vol. 33, pp. 218-242, 1996.

[40] A. J. C. Orbeta, "Poverty, fertility preferences, and family planning practice in the Philippines," Philippine Institute for Development Studies, Discussion papers, series 2005-22.

[41] R. Alonzo, A. Balisacan, D. Canlas et al., "Population and poverty: the real score. University of the Philippines, School of Economics," Discussion Paper 415. 2004, http://www.econ.upd .edu.ph/respub/dp/pdf/DP2004-15.pdf.

[42] A. F. Odusola, "Poverty and fertility dynamics in Nigeria: a micro evidence. Paper presented at the conference of the Centre for the Study of African Economies of Oxford University by Head Research NCEMA," Ibadan, 2002, http://www.csae.ox.ac .uk/conferences/2002-UPaGiSSA/papers/Odusola-csae2002 .pdf.

[43] D. Kothari and S. Krishnaswamy, "Breaking the vicious circle of poverty and fertility through streamlining supply management. A case study of India," Indian Institute of Health Management Research (IIHMR), Jaipur, India, Working Paper no 3, 1998.

[44] A. J. Mturi, Infant and child mortality and its effects on fertility in Kenya [M.S. thesis], Cairo Demographic Centre, 1989.

[45] S. K. Sanderson, "An evolutionary interpretation of fertility decline: new evidence," Population and Environment, vol. 22, no. 6, pp. 555-563, 2001.

[46] J. Bongaarts, "Trends in unwanted childbearing in the developing world," Studies in Family Planning, vol. 28, no. 4, pp. 267-277, 1997.
[47] G. S. Becker, A Treatise on the Family, Harvard University Press, Cambridge, Mass, USA, 1991.

[48] M. Rahman, J. DaVanzo, and A. Razzaque, "When will Bangladesh reach replacement-level fertility? The role of education and family planning services," Report of the Expert Group Meeting on Completing the Fertility Transition, New York, NY, USA, 2002, http://www.un.org/esa/population/publications/completingfertility/2RevisedRAHMANpaper.PDF.

[49] R. Hakkert, "Levels and determinants of wanted and unwanted fertility in Latin America," 2001, http://archive.iussp.org/Brazil2001/s50/S56_03_Hakkert.pdf.

[50] W. Njogu, "Trends and determinants of contraceptive use in Kenya," Demography, vol. 28, no. 1, pp. 83-99, 1991.

[51] D. K. Guilkey and S. Jayne, "Fertility transition in Zimbabwe: determinants of contraceptive use and methods choice," Population Studies, vol. 51, no. 2, pp. 173-189, 1997.

[52] E. van de Walle and D. Meekers, "Socio-cultural context of family and fertility in sub-Saharan Africa," Paper prepared for the African Development Bank Conference on Population Growth and Sustainable Growth in Africa: Trends, Issues and Policies, Abidjan, Côte d'Ivoire, 1992.

[53] J. Chege, "Interventions linking gender relations and violence with reproductive health and HIV: rationale, effectiveness and gaps," Agenda Special Focus, 2005, http://www.populationcouncil.net/pdfs/frontiers/journals/Agenda_Chege05.pdf.

[54] U. C. Isiugo-Abanihe, "Reproductive motivation and familysize preferences among Nigerian men," Studies in Family Planning, vol. 25, no. 3, pp. 149-161, 1994.

[55] T. Gebreselassie, "Spousal agreement on reproductive preferences in sub-Saharan Africa," DHS Analytical Studies 10, Macro International Inc. Calverton, Md, USA, 2008.

[56] J. B. Casterline and L. O. El-Zeini, "The estimation of unwanted fertility," Demography, vol. 44, no. 4, pp. 729-745, 2007.

[57] J. Johnson-Hanks, "Natural intentions: fertility decline in the African demographic and health surveys," American Journal of Sociology, vol. 112, no. 4, pp. 1008-1043, 2007.

[58] I. Bhushan and K. Hill, "The measurements and interpretation of desired fertility," Johns Hopkins Population Center, Baltimore, MD, USA, Papers WP 95-1, 1995.

[59] S. O. Rutstein and G. Rojas, Guide to DHS Statistics, ORC Macro International Inc, Calverton, Md, USA, 2006. 

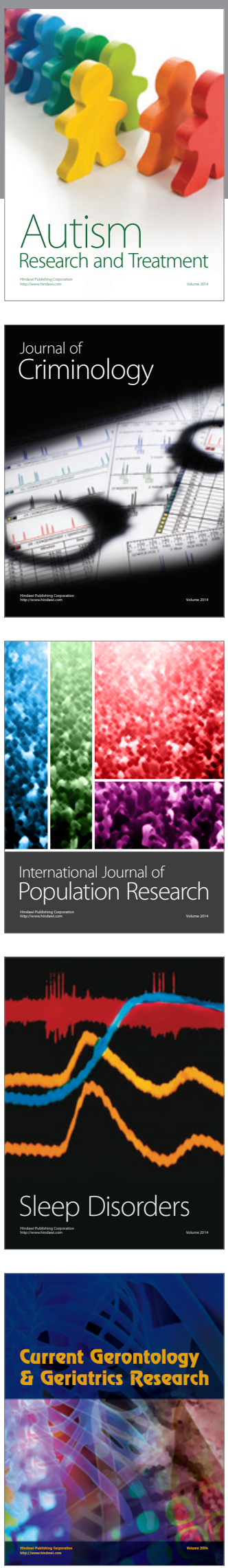
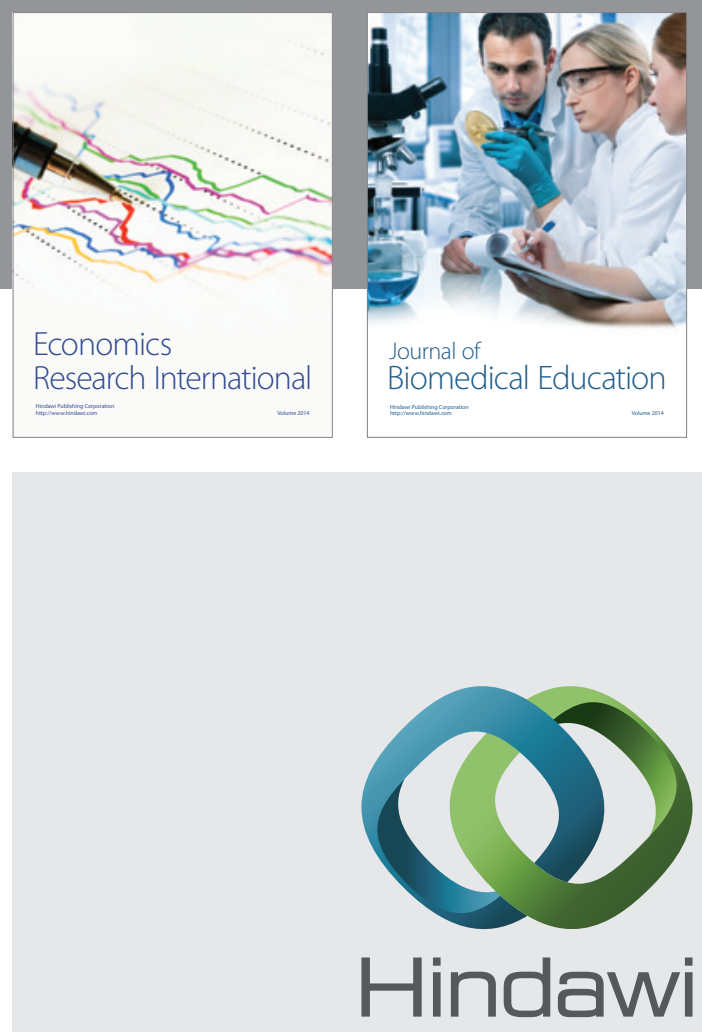

Submit your manuscripts at

http://www.hindawi.com
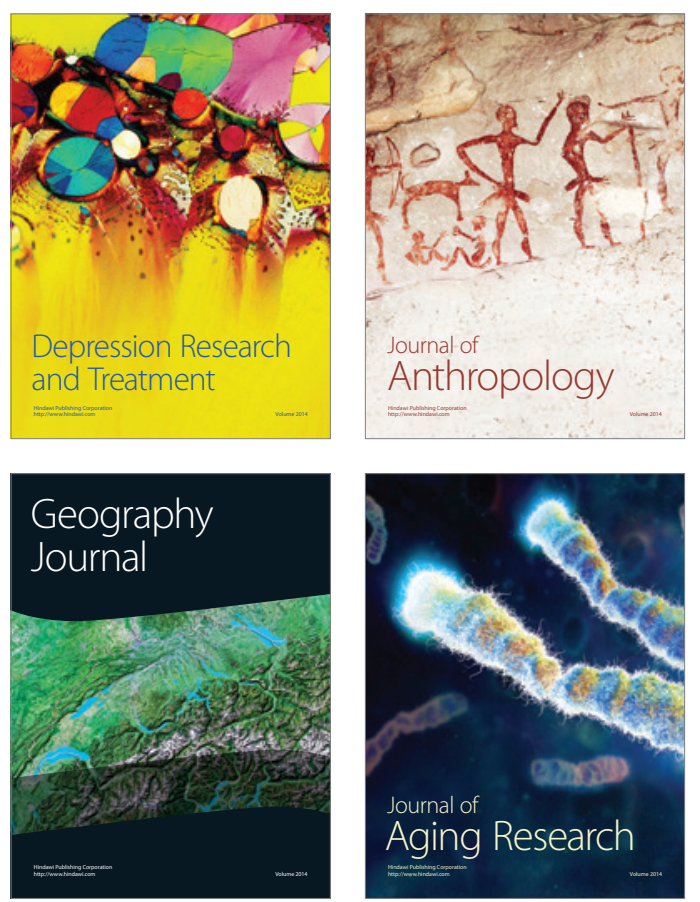
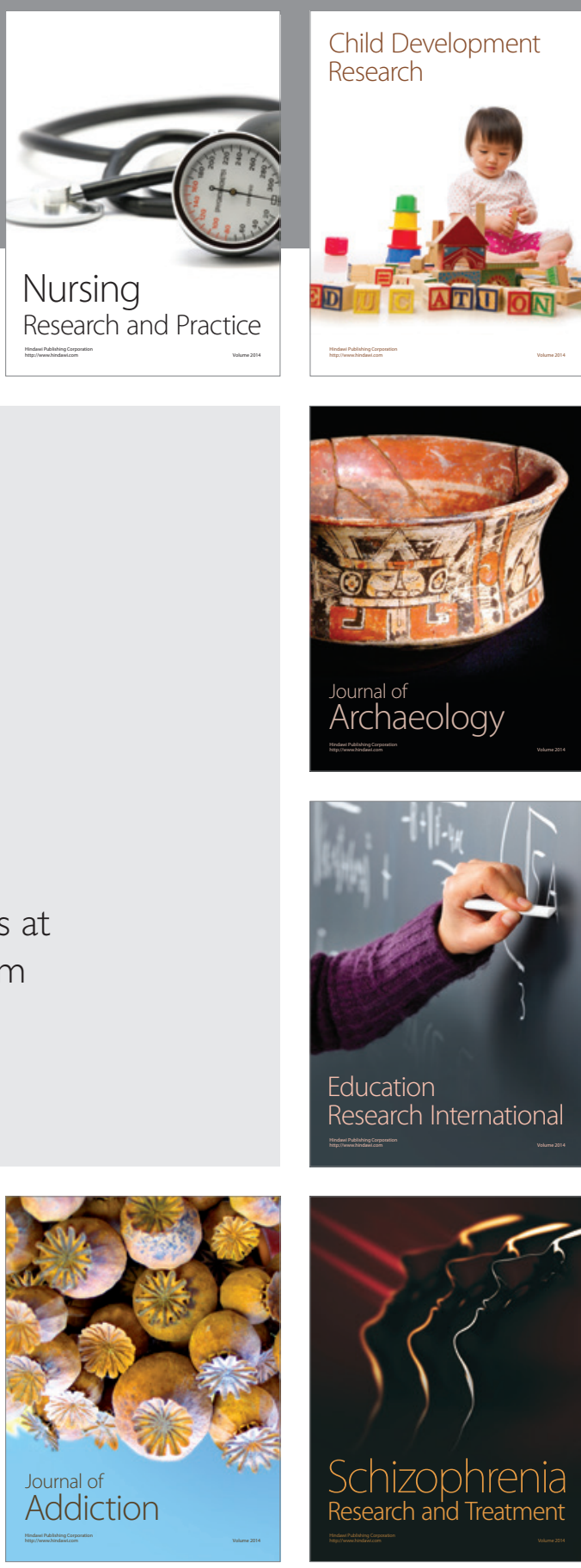

(D)
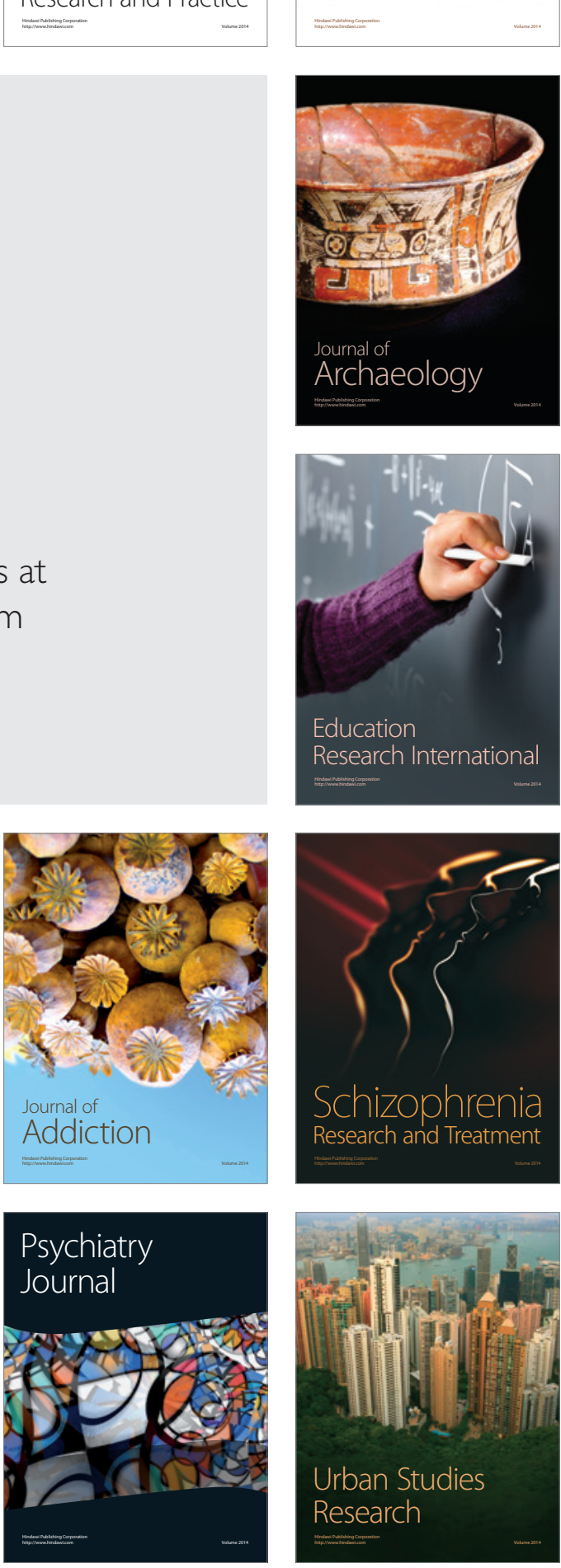